\title{
Diagnóstico de Gestão de Resíduos da Construção Civil no Município de Olinda
}

Farias, A. B.

Escola Politécnica de Pernambuco Universidade de Pernambuco 50.720-001 - Recife, Brasil andrea.faria@upe.br

\author{
Fucale, S. P. \\ Escola Politécnica de Pernambuco \\ Universidade de Pernambuco \\ 50.720-001 - Recife, Brasil
}

\author{
Gumão, A. D. \\ Escola Politécnica de Pernambuco \\ Universidade de Pernambuco \\ 50.720-001 - Recife, Brasil
}

A volumosa geração de residuos originada pelas atividades construtivas tem provocado problemas
de ordem social, ambiental e econômica devido a sua destinação final, já que na grande maioria dos
casos, estes são depositados incorretamente. Diante deste cenário surgiu, em 2002, a Resolução
CONAMA (Conselho Nacional do Meio Ambiente) no 307 , que estabelece diretrizes, critérios e pro-
cedimentos para a gestão dos Resíduos da Construção Civil (RCC). Com isso, passa a existir a neces-
sidade de se analisar a situação da gestão dos RCC nos diversos municípios brasileiros. Desta
maneira, esta pesquisa buscou diagnosticar a atual situação destes resíduos em Olinda/PE, através de
visitas no município, entrevistas estruturadas, mapeamento dos pontos irregulares, entre outros.
Portanto, o presente trabalho espera contribuir para a definição de um modelo de gestão dos RCC
mais adequado às características regionais, para a adequação da construção civil ao contexto de re-
sponsabilidade ambiental e desenvolvimento sustentáve.

\begin{abstract}
The bulky waste generation originated by constructive activity has caused problems in social, environmental and economical due to its final disposal, since in most cases, these are deposited incorrectly. On this scenario emerged in 2002, the Resolution CONAMA (national environmental Council) $n^{\circ} 307$ establishing guidelines, criteria and procedures for the management of civil construction waste (CCW). With this, it's necessary to analyse the situation of the management of $C C W$ in several brazilian municipalities. This research sought to diagnose the current situation of the management of this waste in Olinda/PE through visits in the municipality, structured interviews, mapping of irregular points, among others. Therefore, this paper is expected to contribute to defining a management model of the $C C W$ more appropriate to regional characteristics, to the adequacy of construction to the context of environmental responsibility and sustainable development.
\end{abstract}




\section{Introdução}

O descontrolado crescimento da população mundial impulsionou o aumento da demanda por bens e serviços, o que gerou uma sociedade de consumo e desperdício como jamais acontecera na história. Paralelamente, aliado ao avanço tecnológico, o progresso da indústria propiciou a criação de novos produtos, cujo uso indiscriminado levou à dilapidação dos recursos naturais. Tradicionalmente, os resíduos gerados durante a produção e ao final de sua vida útil eram descartados em aterros irregulares [1].

Os resíduos originados pela indústria da construção civil compõem um grande percentual dos resíduos produzidos em meios urbanos brasileiros. Estima-se que esse número pode chegar a $49 \%$ em Recife/PE [2], cidade adjacente ao município de Olinda, sendo em média, 20\% destes resíduos coletados por empresas autorizadas pelo poder público. Porém, deste último percentual, apenas $1 \%$ receberam destinação correta, ficando 353.606 toneladas em áreas clandestinas no ano de 2004.

Apesar dos altos índices de desperdício não serem uma exclusividade da indústria da construção, estes são destaque porque o consumo desnecessário de material resulta em uma alta produção de resíduos, causa diversos transtornos nas cidades, reduz a disponibilidade futura de materiais e energia, e provoca uma demanda desnecessária no sistema de transporte [3].

A inexistência de política pública, ausência de compromisso dos geradores e coletores de RCC e falta de consciência ambiental por parte da sociedade são responsáveis pelo aparecimento de depósitos clandestinos que, conseqüentemente, originam impactos ambientais como assoreamento de rios e córregos e obstrução de sistemas de drenagem; impactos sociais, visto que ocorre a proliferação de agentes transmissores de doenças e surgimento de catadores informais sem capacitação que trabalham em condições desumanas; e impactos financeiros, pois o consumo desnecessário de materiais construtivos gera aumento no custo da obra.

\section{Objetivo}

Esta pesquisa tem como objetivo apresentar um diagnóstico da situação dos Resíduos da Construção Civil (RCC) no município de Olinda/PE a fim de fornecer subsídios para o desenvolvimento de soluções adequadas para a gestão desses resíduos por parte dos diversos agentes envolvidos no processo, visando, dessa maneira, reduzir os impactos ambientais causados pela indústria da construção civil.

\section{Metodologia}

O modelo para diagnosticar a situação dos RCC em Olinda/PE envolveu a descrição dos aspectos básicos do município, a caracterização quantitativa dos resíduos, a composição percentual dos materiais presentes nos resíduos e o mapeamento de áreas de deposição clandestina. Além disso, houve a identificação das ações de adequação à Resolução CONAMA no 307 (2002) e o contato direto com os atores envolvidos (por meio de entrevistas).

\subsection{Pesquisa documental}

A coleta de dados consistiu no levantamento do estado da arte relativo às características do município de Olinda/PE, das quais várias informações foram pesquisadas, como história, extensão territorial, localização, número de habitante da cidade, nível cultural, relevo, bacias hidrográficas existentes, desenvolvimento do setor econômico, entre outros.

\subsection{Entrevistas}

Elaborou-se um formulário (Anexo 01) com foco nas informações e dados fundamentais para o desenvolvimento desta pesquisa. Em seguida, o mesmo foi aplicado no setor de Limpeza Urbana do município, em pessoas qualificadas para tal.

$\mathrm{Na}$ identificação das ações de adequação à Resolução CONAMA no 307 (2002), aplicou-se entrevistas estruturadas, todas agendadas e com roteiros diferenciados, entre os responsáveis pelos canteiros de obras das construtoras mais representativas do município (Anexo 02), pelas empresas coletoras e transportadoras mais atuantes de Olinda (Anexo 03) e pelo Aterro Controlado de Aguazinha (Anexo 04).

Nesta etapa foram consideradas as 04 (quatro) construtoras mais influentes de Olinda, com canteiro de obras do tipo multifamiliar, selecionadas por meio de visitas preliminares, visto que estas empresas são geradoras e responsáveis pelos impactos ambientais causados pelos resíduos e, em alguns casos, possuem um baixo nível tecnológico e um elevado nível de perdas de materiais

Com relação às empresas coletoras e transportadoras de RCC, foram selecionadas as 02 (duas) mais atuantes do município, selecionadas por meio de indicações das construtoras contactadas na etapa anterior, já que a Prefeitura de Olinda não possui o cadastramento destas. 
Para explorar mais amplamente a questão dos RCC e fornecer a devida dimensão dos impactos no Aterro Controlado de Aguazinha, entrevistou-se o responsável por este local.

Depois de verificar as ações atuais praticadas pelos atores em questão, com base na técnica de observação direta intensiva, foram realizados registros fotográficos para posterior análise.

\subsection{Mapeamento de depósitos irregulares de RCC}

Realizou-se uma pesquisa de campo para a identificação dos diversos pontos de deposição irregular, por meio de informações de moradores do município, de empresas construtoras, de empresas coletoras e de autônomos que transportam os resíduos originados pelo setor da construção civil, além da observação direta do município.

Identificou-se os locais de depósitos ilegais e tomou-se as coordenadas geográficas com um aparelho GPS tipo GT Sound, modelo 411 - BT. Posteriormente, os pontos em questão foram plotados a partir da utilização do programa Google Earth versão 5.0.1.

Realizou-se ainda nesta fase o registro fotográfico dos pontos de deposição identificados.

\subsection{Estimativa de geração de RCC}

A metodologia para a estimativa de geração de RCC mais utilizada no âmbito brasileiro é a proposta pelo autor [4], a qual pode ser realizada a partir de três bases de informação:

- estimativa da área construída no município;

- transporte de RCC pelas empresas de coleta;

- deposição dos resíduos nas áreas utilizadas como destino final de RCC.

Para realização desta fase, foram coletados dados no Departamento de Controle Urbano, da Secretaria de Planejamento, Transporte e Meio Ambiente da Prefeitura Municipal de Olinda (SEPLAMA). Obteve-se as licenças de construção expedidas nos anos de 2006 e 2009, com suas respectivas áreas, para elaboração dos cálculos de resíduos gerados, aplicando-se taxa de geração de RCC determinada.

Em seguida, realizou-se uma visita ao Departamento de Limpeza Urbana de Olinda para coleta de informações com relação à deposição de RCC em áreas utilizadas como destino final, a fim de estimar o volume depositado destes resíduos em pontos distintos do município. Com os dados a serem fornecidos, a quantidade de RCC coletado nesses pontos foram acrescidos aos valores das demais bases de informação.

\subsection{Composição dos RCC}

Para a caracterização gravimétrica dos resíduos originados pela construção civil em Olinda, coletou-se 04 (quatro) amostras de RCC em depósitos clandestinos, onde cada uma delas foi recolhida em um local distinto do município, pesando $13 \mathrm{~kg}$, mesmo valor utilizado por outro pesquisador, em estudo de RCC no município de Recife [2]. Posteriormente, as amostras foram acondicionadas em baldes, com volume de 20 litros, identificados e transportados para um canteiro de obras de Olinda, a fim de se iniciar o ensaio propriamente dito.

As amostras de RCC foram espalhadas sobre uma lona plástica, com o objetivo de não haver mistura com o solo. Em seguida, cada amostra foi separada tátil-visualmente, por tipo de constituinte, ou seja, em concreto, tijolo, argamassa, cerâmica, material miúdo, mármore/granito, material misto (tijolo e argamassa) e outros (papel, plástico, madeira e vidro). Pesando-se, em seguida, cada constituinte, permitindo, assim, a determinação da porcentagem em massa de cada tipo de material da amostra, ou seja, a composição gravimétrica da amostra. A Figura 1 mostra os materiais já segregados.

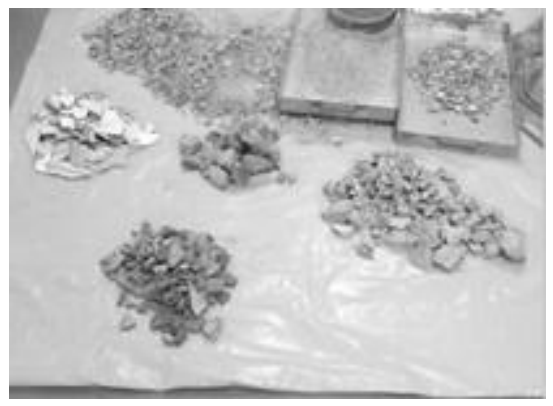

Fig 1. Separação tátil-visual da amostra.

\section{Resultados}

\subsection{Indicadores Básicos do Município}

Fundada em 1535, o município de Olinda é considerado Patrimônio Histórico e Cultural da Humanidade pela UNESCO (United Nations Educational, Scientific and Cultural Organization) desde 1982, sendo uma das mais bem preservadas cidades coloniais do Brasil (Figura 02). Com uma área de $43,55 \mathrm{~km}^{2}$, é a terceira maior cidade do estado de Pernambuco, possuindo $36,73 \mathrm{~km}^{2}(98 \%)$ de área urbanizada e $6,82 \mathrm{~km}^{2}$ de área rural [5]. Sua população tem 397.268 habitantes, representando $9.122,11$ pessoas por $\mathrm{km}^{2}[6]$.

$\mathrm{Na}$ Figura 2, tem-se a vista geral de um dos pontos turísticos de Olinda/PE. 


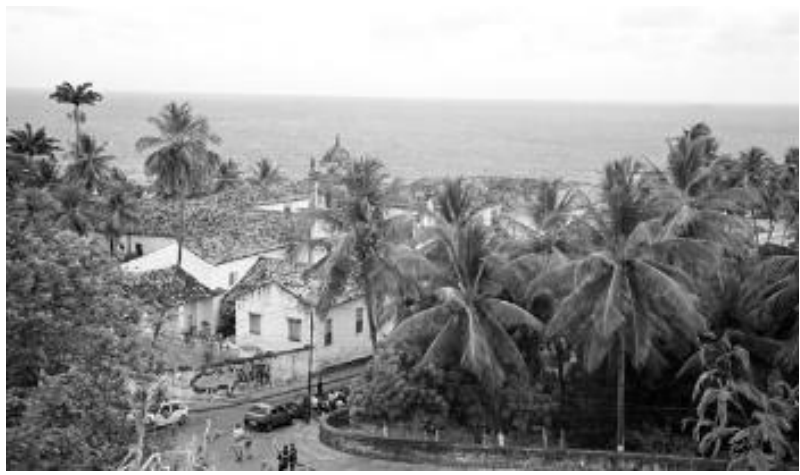

Fig 2. Imagem atual de Olinda/PE [7].

Situada na região nordeste do Brasil, Olinda está distante $6 \mathrm{~km}$ da capital do estado de Pernambuco, Recife. Limita-se ao norte com o município de Paulista, ao sul e oeste com Recife e a leste com o Oceano Atlântico. O município está a uma altitude de $16 \mathrm{~m}$, seu clima é quente e úmido, com temperatura média anual de $27^{\circ} \mathrm{C}$ e amplitude térmica de $5^{\circ} \mathrm{C}$. Sua posição geográfica é $08^{\circ} 01^{\prime} 48^{\prime \prime}$ de latitude e $34^{\circ} 51^{\prime} 42^{\prime \prime}$ de longitude.

Olinda tem sua importância não só pela história do local, mas também pela economia, visto que agrega grande valor ao PIB pernambucano, advindo do forte berço turístico que ela representa. Embora o município não possua um pólo industrial, destaca-se a importância do setor de serviços na geração de emprego e renda e para o crescimento econômico do município [8]. Segundo dados da Prefeitura de Olinda, dos 62.033 trabalhadores do município, mais da metade, 39.196 ou $63,19 \%$, desenvolve atividades econômicas na área de serviços [5].

As belezas naturais, a cidade ainda começando a se verticalizar e a vida tranquila em Olinda tem feito com que certa parte da população procure o município como refúgio e como sinônimo de descanso. Observa-se, através dos anos, o forte crescimento populacional do município, como pode ser comprovado na análise da Figura 3 [8] Com isso, torna-se evidente a necessidade de uma infra-estrutura para a população e proceder ao desenvolvimento de forma sustentável.

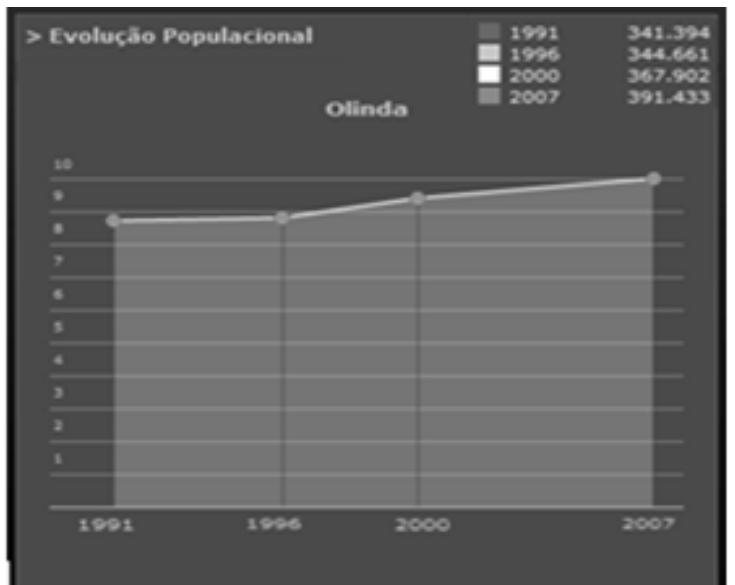

Fig 3. Crescimento populacional de Olinda [8].

\subsection{Construção civil em Olinda}

Para efeito deste estudo foram consideradas as informações obtidas a partir da Prefeitura de Olinda, no Departamento de Controle Urbano da SEPLAMA, das áreas licenciadas, conforme Tabela 1.

Tabela 1. Áreas licenciadas para construção em Olinda.

\begin{tabular}{|c|c|c|}
\hline \multirow{2}{*}{ Olinda } & \multicolumn{2}{|c|}{ Parâmetros analisados } \\
\cline { 2 - 3 } & $\begin{array}{c}\text { Área total } \\
\text { licenciada } \\
\left(\mathbf{m}^{\mathbf{2}}\right)\end{array}$ & $\begin{array}{c}\text { \% licenciado } \\
\text { (ano base 2006) }\end{array}$ \\
\hline 2006 & $38.634,11$ & - \\
\hline 2007 & $47.530,93$ & 23 \\
\hline 2008 & $106.477,07$ & 176 \\
\hline 2009 & $86.432,40$ & 124 \\
\hline
\end{tabular}

Em 2008, tomando-se como parâmetro o ano de 2006, houve um aumento na quantidade de área licenciada da ordem de $176 \%$, o que representa um crescimento da indústria da construção civil no município 2,76 vezes maior. Em 2009, este crescimento diminui para $124 \%$ sendo um valor de grande expressão.

Observa-se um aquecimento imobiliário significativo a partir de 2008, o que demonstra um momento propício para a elaboração dessa pesquisa, face ao volume crescente de RCC gerado.

De acordo com as informações obtidas pela Diretoria de Limpeza Urbana (DLU) do município em estudo, não há lei específica para a gestão de RCC em Olinda, porém as diretrizes adotadas pela mesma são orientadas pela Resolução CONAMA nº 307 (2002).

Outro aspecto a se destacar é a falta de local para deposição final do RCC originado no município para des- 
tinação/tratamento final dos resíduos gerados pelo pequeno e grande gerador, uma vez que o único aterro existente é o Aterro Controlado de Aguazinha, que recebe, desde 2003, no máximo 03 (três) caçambas de RCC por transportador, mas não possui a quantidade exata deste material depositado, pois na entrada o mesmo é registrado como "volumosos", incluindo, materiais oriundos da conservação, como varrição e capinação, bem como algum resíduo domiciliar, se misturado.

Olinda não possui um cadastro das empresas coletoras de RCC que atuam no município. Apesar do Aterro Controlado de Aguazinha não receber RCC diretamente das empresas geradoras, a prefeitura é responsável pela coleta de resíduos depositados em pontos irregulares. Para tal recolhimento a DLU utiliza-se de empresas coletora terceirizadas, previamente cadastradas, as quais descarregam os resíduos no Aterro Controlado de Aguazinha, como volumosos, já que o material recolhido não pode se dizer que é só RCC. Diariamente, cada uma dessas empresas pode descarregar até 03(três) caçambas no Aterro do município.

A Diretoria de Limpeza Urbana recolhe diariamente até 300 litros, por unidade habitacional, de RCC ou volumosos deixados na porta da residência. Esta coleta é realizada por estas empresas coletoras terceirizadas até a quantidade já mencionada.

A quantidade de habitantes de Olinda é da ordem de 391.433, sendo atendido pelo sistema de coleta de resíduos 383.304 habitantes, que vivem na área urbana do município.

$\mathrm{Na}$ DLU não se tem dados referentes ao volume total de RCC gerado no município, nem da quantidade depositada em pontos irregulares e coletada pela própria prefeitura. Não há informação sistematizada dos dados. É certo que uma diminuição no volume de RCC resultaria numa diminuição dos custos operacionais do aterro e também no aumento da sua vida útil.

Não há no município a existência de política de gestão dos RCC ou uma previsão de implantação de Projeto de Gerenciamento de Resíduos da Construção Civil (PGRCC), nos canteiros de obras para os grandes geradores, determinado pela Resolução CONAMA n 307.

O Aterro Controlado de Aguazinha tinha previsão de fechamento para julho/2010, porém diante da impossibilidade real do município deixar de colocar seus resíduos no aterro, este prazo foi estendido até dezembro/2010. A partir de 2011, os resíduos serão encaminhados para um aterro privado existente em Igarassu. Vale ressaltar que hoje o custo de operação mensal do aterro de Aguazinha é da ordem de $\mathrm{R} \$ 300.000,00$ e no novo aterro (privado) esse valor será de R\$617.000,00, acarretando um aumento de $106 \%$.
O Aterro de Aguazinha será transformada em uma estação de transbordo onde os caminhões que atualmente lá descarregam, descarregarão o volume de resíduos transportado em outro caminhão, de capacidade bem superior, e que transportará esses resíduos para o CTR Pernambuco, em Igarassu, visando uma diminuição nos custos de transporte.

\subsection{Diagnóstico}

\subsubsection{Canteiro de Obra}

Inicialmente, no que se refere às ações realizadas pelas empresas construtoras nos canteiros de obras do município de Olinda, o estudo buscou dados sobre a existência de certificação no PBQP-H (Programa Brasileiro de Qualidade do Habitat) e na ISO (International Organization for Standardization) e o conhecimento da Resolução CONAMA n ${ }^{\circ}$ 307 (2002) por parte do engenheiro responsável pela obra, para definir o nível de normatização e a conscientização sobre a gestão de RCC entre as construtoras mais significativas do município. Dentre as 04 (quatro) empresas pesquisadas, 01 (uma) possui certificação no PBQP-H, 03 (três) têm ISO e 03 (três) engenheiros conhecem a aludida resolução.

Em seguida, as construtoras foram indagadas quanto ao volume de resíduos gerados a fim de identificar se as mesmas possuíam tais informações. Destas, apenas 01 (uma) faz o controle por meio de fichas de produtividade, comparando-se o material adquirido e utilizado na obra, porém não tinha a informação sistematizada para fornecer.

Quando questionados quanto ao fornecimento de orientação aos funcionários no que diz respeito à redução de desperdícios de materiais durante a execução dos trabalhos, todos entrevistados nos canteiros de obras afirmaram oferecê-las. Já com relação às ações específicas que visem à redução de resíduos, constatou-se que apenas 02 (duas) empresas adotam alguma prática. Uma realiza o treinamento dos funcionários, na própria obra, instruindo a melhor forma de execução dos serviços a serem executados, e a outra faz o controle de espessura de fachadas e contra piso, onde há desperdício de material.

Para observar a dimensão da obra e o tratamento dado aos RCC, buscou-se a área construída $\left(\mathrm{m}^{2}\right)$, o volume em $\mathrm{m}^{3}$ da caçamba ou caminhão basculante utilizado e a presença de ações como segregação dos resíduos e reaproveitamento dos mesmos na própria obra. E, a fim de facilitar a análise, compilou-se os resultados na Tabela 2.

Tabela 2. Informações sobre os canteiros de obra. 


\begin{tabular}{|c|c|c|c|c|}
\hline Obra & $\begin{array}{l}\text { Anea } \\
\text { cons- } \\
\text { truída } \\
\left(\mathrm{m}^{\mathrm{T}}\right)\end{array}$ & $\begin{array}{l}\text { Segre- } \\
\text { gaçăo }\end{array}$ & $\begin{array}{l}\text { Reapro- } \\
\text { veitamento } \\
\text { dos RCC }\end{array}$ & $\begin{array}{c}\text { Vohume } \\
\text { da } \\
\text { caçamba } \\
\text { ou } \\
\text { caminhăم } \\
\text { bascu- } \\
\text { lante }\left(\mathrm{m}^{\mathrm{N}}\right)\end{array}$ \\
\hline 01 & 61.104 & Sim & $\begin{array}{l}\text { O material } \\
\text { usado em } \\
\text { atemo é } \\
\text { reutilizado ras } \\
\text { outras obras da } \\
\text { própria } \\
\text { construtora }\end{array}$ & 08 \\
\hline 02 & 15.000 & Sim & $\begin{array}{l}\text { Reutiliza a } \\
\text { madeira, todo } \\
\text { material } \\
\text { possínel para } \\
\text { reatemo e } \\
\text { cerâmica em } \\
\text { trinchos. }\end{array}$ & $\begin{array}{c}\text { Não } \\
\text { informado }\end{array}$ \\
\hline 03 & $5.486,94$ & ผão & $\begin{array}{l}\text { Reutiliza } \\
\text { argamassa } \\
\text { peneirada } \\
\text { como areia }\end{array}$ & 04.205 \\
\hline 04 & 4000 & Sim & $\begin{array}{l}\text { Á massa única } \\
\text { é peneiradae } \\
\text { acresoentada } \\
\text { na mistura do } \\
\text { cimentado para } \\
\text { piso }\end{array}$ & 06.208 \\
\hline
\end{tabular}

Ressalta-se que todos os canteiros de obra são do tipo multifamiliar, pois, considerando as áreas licenciadas, são as mais significativas. $\mathrm{O}$ canteiro de obra 01 tem a maior área construída, pois se trata de dois blocos, com 33 pavimentos e segrega apenas madeira, vendendo-as para padarias; o 02 possui três blocos, com 14 pavimentos; o 03 tem dois blocos e tem uma proposta de implantação da coleta seletiva; e o 04 se trata de um bloco, com 15 pavimentos e segregação de resíduos Classe $\mathrm{B}$, destinando o ferro, plástico, papelão para empresas de reciclagem e madeira para panificadoras.

E, finalizando esta etapa do trabalho, buscou-se informações, junto aos construtores, sobre o responsável pela coleta dos RCC da obra, e se havia conhecimento a respeito da destinação dada aos resíduos e de depósitos irregulares (Tabela 3). Vale frisar que as empresas coletoras entrevistadas nesta pesquisa foram denominadas de A e B.

Tabela 3. Empresas coletoras, destinação final e possíveis locais de depósitos irregulares.

\begin{tabular}{|c|c|c|c|}
\hline $\begin{array}{c}\text { Canteiro } \\
\text { de obra }\end{array}$ & $\begin{array}{c}\text { Empresa } \\
\text { coletora }\end{array}$ & $\begin{array}{c}\text { Destinação } \\
\text { dos RCC }\end{array}$ & $\begin{array}{c}\text { Depósitos } \\
\text { Irregulares }\end{array}$ \\
\hline 01 & Autônomo & $\begin{array}{c}\text { Aterros } \\
\text { legalizados }\end{array}$ & ----- \\
\hline 02 & A & ---- & $\begin{array}{c}\text { Próximo de } \\
\text { canais no } \\
\text { bairo } \\
\text { Bultrins }\end{array}$ \\
\hline 03 & B & ---- & ---- \\
\hline 04 & B & ---- & ---- \\
\hline
\end{tabular}

\subsubsection{Empresa Coletora}

A Prefeitura de Olinda, de acordo com entrevista feita a DLU, não possui o cadastramento das coletoras e transportadoras que operam no município, ou seja, as mesmas não têm licença prévia para atuar no município, exceto quando são contratadas diretamente pela prefeitura para recolhimento dos entulhos encontrados em pontos clandestinos.

Durante a entrevista com a empresa coletora A foi informado que possui 11 anos de funcionamento, atua com 90 caçambas, com volume de $6 \mathrm{~m}^{3}$ cada, cobrando $\mathrm{R} \$$ 150,00 por caçamba. Tem 03 caminhões tipo poliguindastes, opera de segunda a sábado e coleta em média 03 caçambas por dia. Deposita os RCC no Aterro Controlado de Aguazinha ou em terrenos particulares. Não tem conhecimento sobre depósitos clandestinos e não realiza o comércio dos resíduos. Normalmente utiliza a seguinte rota até o Aterro Controlado de Aguazinha: Perimetral, Avenida Beberibe, Presidente Kennedy. A empresa coletora A coletora afirma também que mais de $80 \%$ do material recolhido por ela em Olinda trata-se de RCC, com as participações em percentual expostas na Figura 04. E quando questionada com relação a respeito da implantação de usinas de reciclagem, a mesma se mostrou favorável, porém não possuía nenhuma sugestão.

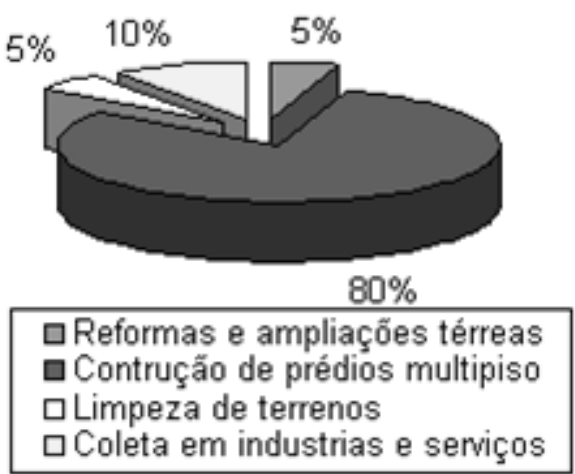


Fig 4. Percentual de atuação da empresa coletora A de acordo com os tipos de serviços.

Já a empresa coletora B tem 13 anos de operação, com 20 funcionários, possui 150 caçambas disponíveis para o transporte de resíduos e cobra $\mathrm{R} \$ 130,00$ por caçamba. Tem caminhões do tipo poliguindastes, deposita os RCC no Aterro Controlado de Aguazinha e em área particular, não licenciada, disponibilizada pelo proprietário para este fim em Camaragibe. A empresa B afirma que $90 \%$ dos materiais coletados são RCC, com participação em percentual mostrada na Figura 4.

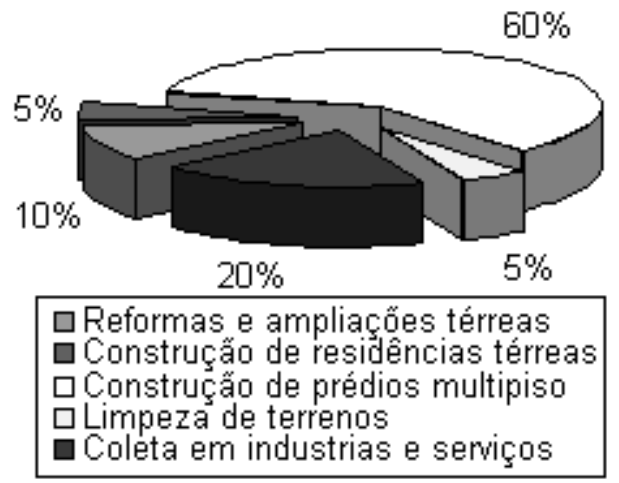

Fig 5. Percentual de atuação da empresa coletora B de acordo com os tipos de serviços.

\subsubsection{Destinação final}

O município de Olinda possui um aterro controlado chamado de Aguazinha, situado na zona norte da Região Metropolitana do Recife, possuindo uma área de 19 hectares. É responsável por receber os resíduos coletados pela prefeitura, aproximadamente 450 toneladas por dia, entre matéria orgânica (resíduos domiciliares), volumosos (entulhos e raspagem), recicláveis (vidro, plástico, metal e outros), acumulando aproximadamente $12.000,00$ toneladas/mês. O material proveniente da poda é depositado em área separada para retirada de galhos mais grossos, utilizados como lenhas, e o restante dos resíduos é levado para as células. É dito que o Aterro Controlado de Aguazinha não recebe RCC, porém sabe-se que ele entra no aterro como material volumoso, segundo informações do engenheiro residente do local.

O serviço de coleta de resíduos atende aproximadamente $90 \%$ da população de Olinda, a urbana. O material chega ao aterro de Aguazinha através de caminhões de empresa contratada para executar o serviço regular de limpeza urbana da cidade e também de outras empresas terceirizadas que trabalham no município diretamente contratadas pelos grandes geradores. As empresas particulares pagam para depositar os resíduos em Aguazinha.

A presença do Grupo de Resíduos Sólidos (GRS) da Universidade Federal de Pernambuco (UFPE) é um dos pontos fortes para o gerenciamento, tornando a parte operacional do aterro tão boa quanto à de um aterro privado.

\subsection{Mapeamento dos pontos irregulars}

Nesta etapa da pesquisa, realizada durante o primeiro semestre de 2010, foram identificados 30 pontos de deposição irregular de RCC, encontrados, normalmente, em áreas de preservação ambiental, como mangues e lagoas; cursos d'água; vias publicas; e próximo a construções habitacionais ilegais de populações de baixa renda.

Na Figura 5 é apresentado o mapa do município de Olinda, com a locação dos 30 (trinta) pontos de deposição ilegal, em amarelo. Em vermelho, estão identificados os 04 pontos irregulares, de maior volume, nos quais foram realizadas coletas de amostras de RCC para o ensaio de composição gravimétrica.

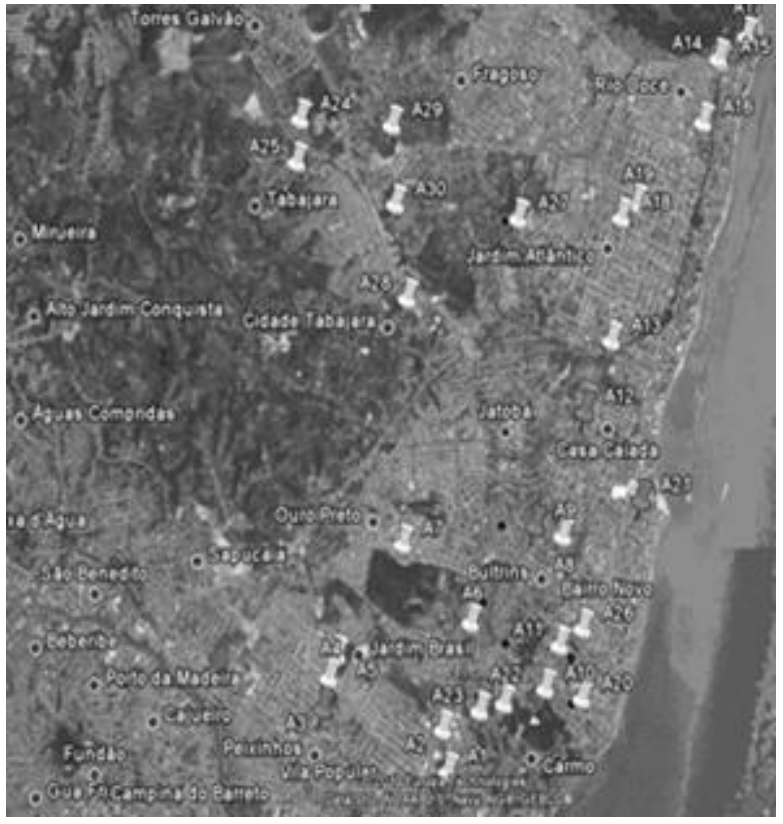

Fig 5. Locação dos pontos de deposição clandestina [9].

\subsection{Estimativa de geração de RCC}

Em uma das obras visitadas foi possível coletar a informação de dados de geração de RCC de outra obra da 
mesma construtora, que estava em fase de entrega e por isso foi possível condensar as informações.

A obra estudada é uma edificação vertical, de uso multifamiliar, com área construída de $6.042,43 \mathrm{~m}^{2}$ (19 pavimentos tipo, com 2 apartamentos por andar, e mais 2 pavimentos de garagem). Foram utilizadas 128 caçambas com resíduos, as quais possuíam $5 \mathrm{~m}^{3}$ de volume cada. Com isso, o volume gerado de resíduos foi da ordem de $640 \mathrm{~m}^{3}$, ou seja, para cada $\mathrm{m}^{2}$ de área construída, gera-se $0,11 \mathrm{~m}^{3}$ de resíduo.

Considerando o peso específico do resíduo de 1,4 ton. $/ \mathrm{m}^{3}$ [2], tem-se que:

$640 \mathrm{~m}^{3} \times 1,4$ ton $/ \mathrm{m}^{3}=896$ toneladas de resíduo.

Logo, a taxa de geração da obra pesquisada foi de:

$$
\mathrm{TG}=\frac{896.000}{6042,43}=148,28 \mathrm{~kg} / \mathrm{m}^{2} \text {, }
$$

sendo $\mathrm{TG}=$ taxa de geração.

A taxa de geração encontrada de $148,28 \mathrm{Kg} / \mathrm{m}^{2}$ de área construída está muito próxima dos valores apresentados em [3], ou seja, 150,00 Kg/m².

A estimativa da geração de resíduo por $\mathrm{m}^{2}$ construído possibilitou determinar a geração de RCC ao longo dos anos, a partir do licenciamento para construção no município.

Para o cálculo do volume de resíduos gerados, a Taxa de Geração encontrada foi utilizada para os anos de 2006 a 2009.

Utilizando-se desta metodologia, e com os dados coletados das áreas licenciadas dos anos de 2006 a 2009, foi possível estimar o quantitativo de RCC gerado ao longo do ano, do mês e/ou dia, conforme Tabela 4.
Tabela 4. Geração estimada de RCC por área licenciada para con-

\begin{tabular}{|c|c|c|c|c|}
\hline \multirow{2}{*}{$\begin{array}{l}\text { Parâmetros } \\
\text { analisados }\end{array}$} & \multicolumn{4}{|c|}{ Olinda } \\
\hline & 2006 & 2007 & 2008 & 2009 \\
\hline $\begin{array}{l}\text { Área total } \\
\text { licenciada } \\
\left(\mathrm{m}^{2}\right)\end{array}$ & $38.634,11$ & $47.530,93$ & $106.477,07$ & $86.432,40$ \\
\hline $\begin{array}{c}\text { Taxa de } \\
\text { geração } \\
\text { RCC } \\
\left(\mathrm{Kg} / \mathrm{m}^{2}\right)\end{array}$ & 148,28 & 148,28 & 148,28 & 148,28 \\
\hline $\begin{array}{c}\text { Geração de } \\
\text { RCC } \\
\text { (ton/ano) }\end{array}$ & $5.728,67$ & $7.047,89$ & $15.788,42$ & $12.816,20$ \\
\hline $\begin{array}{c}\text { Geração de } \\
\text { RCC } \\
\text { (ton'mês) }\end{array}$ & 477,39 & 587,32 & $1.315,70$ & $1.068,02$ \\
\hline $\begin{array}{c}\text { Geraçäo de } \\
\text { RCC } \\
\text { (ton/dia) }\end{array}$ & 18,36 & 22,59 & 50,60 & 41,08 \\
\hline
\end{tabular}
strução.

As obras licenciadas no ano de 2009 devem gerar um volume de RCC da ordem de 12.816,20 ton, que precisa ter monitoramento do seu destino final.

\subsection{Composição dos RCC}

A composição das amostras foi determinada a partir da coleta de amostras em 04 (quatro) pontos distintos da cidade de deposição irregular, conforme indicados na Figura 5. Elas foram coletadas manualmente, e procurando-se obter uma amostra representativa.

Depois, essas amostras foram pesadas e segregadas da seguinte forma: concreto; argamassas; cerâmicas (telhas e tijolos); revestimentos; madeira e outros (plásticos, metais, dentre outros).

Inicialmente, verificou-se os pesos de cada elemento e em seguida calculou-se os seus percentuais. Foi feita uma média aritmética dos resultados encontrados e elaborada a Figura 6. 


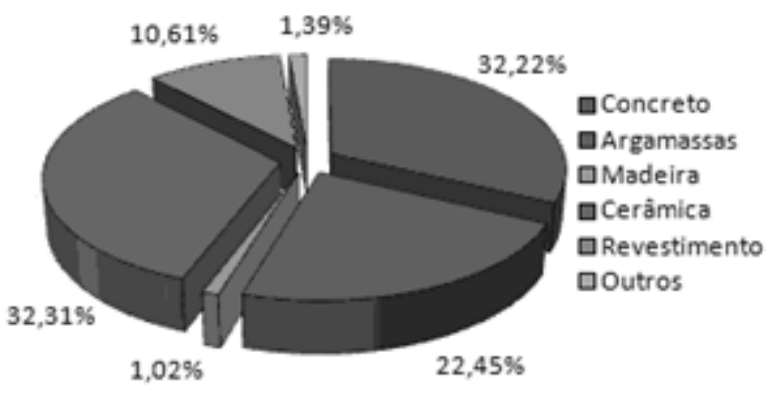

Fig 6. Composição gravimétrica do RCC em Olinda/PE.

É possível verificar, nas amostras, um grande percentual de concreto $(32,22 \%)$ e argamassa $(22,45 \%)$. Material nobre e de alta representatividade no custo final das obras, este elemento necessita ser reutilizado no processo construtivo das obras, justificando estudos especiais para o seu reaproveitamento, em função do alto índice de perda associado. Os demais elementos, como os materiais cerâmicos $(32,31 \%)$ e os revestimentos $(10,61 \%)$ também com altos índices de perdas, justificam a necessidade de desenvolvimento de tecnologias que promovam a redução de suas perdas, além da reutilização e reciclagem, como medida de redução de custos e dos impactos ambientais gerados com a produção desse RCC.

Resultados semelhantes, no que se refere ao percentual de concreto e argamassa, foram encontrados por [10] com 69\% em São Carlos, 33\% em São Paulo, 59\% em Ribeirão Preto e 53\% em Salvador e [2] com 38\% em Recife.

\section{Considerações finais}

Assim como grande parte dos municípios brasileiros, Olinda está distante de solucionar os problemas decorrentes dos resíduos da construção civil. A falta de definição de local apropriado para destinação final dos resíduos, por parte do município, acarreta em deposições clandestinas espalhadas por toda a cidade, provocando grandes impactos ambientais, sociais e problemas de limpeza pública. Outro ponto a ressaltar é a falta de conhecimento dos volumes de resíduos produzidos pelos grandes geradores, ou seja, os construtores que desenvolvem suas atividades em Olinda/PE. Estudos relativos à gestão dos resíduos da construção civil são preponderantes à administração do município.

A análise do setor da construção civil dos últimos anos no município de Olinda, observado através das áreas de construção licenciadas, tem mostrado tendências de crescimento urbano com conseqüente aumento na produção de resíduos.
De acordo com os resultados obtidos no diagnóstico da situação dos RCC em Olinda, conclui-se que a falta de informações tanto por parte dos órgãos municipais responsáveis pelo gerenciamento dos resíduos, bem como por parte das empresas construtoras, grandes geradoras de RCC, principalmente com relação às quantidades geradas e o monitoramento da sua destinação final, torna difícil programar ações que visem a um crescimento sustentável do município.

Há necessidade de se fornecer elementos à população em geral, visando proporcionar um autodesenvolvimento de conscientização ambiental, primordial para a iniciação de passos que demonstrem o tamanho da questão abordada.

\section{Referências}

[1] J.C., Marques Neto. Gestão dos Resíduos de Construção e Demolição no Brasil. São Carlos: Rima, 2005.

[2] F.P., Carneiro. Diagnóstico e Ações da Atual Situação dos Resíduos de Construção e Demolição na Cidade do Recife. Dissertação (Mestrado em Engenharia Urbana) - Programa de Pós-Graduação em Engenharia Urbana, Universidade Federal da Paraíba, João Pessoa, 2005.

[3] A.D., Gusmão. Manual de Gestão dos Resíduos da Construção Civil. Recife/PE. Gráfica Editora, 2008.

[4] T.P., Pinto. Metodologia para a Gestão Diferenciada de Resíduos Sólidos da Construção Urbana. Tese de Doutorado, Escola Politécnica da Universidade de São Paulo, São Paulo, 1999.

[5] Site da Internet: http://www.olinda.pe.gov.br/. Visitado pela última vez em 01/08/2010.

[6] Site da Internet:

http://www.ibge.gov.br/cidadesat/. Visitado pela última vez em 16/04/2010.

[7] Site da Internet:

http://www.casadacul-

tura.org/br/pe/olinda/Olinda_cidade_predios/12 OlindaVistaGera_grd.jpg. Visitado pela última vez em 01/08/2010.

[8] Site da Internet:

http://www.ibge.gov.br/cidadesat/painel/painel.php? codmun $=260960$. Visitado pela última vez em 01/08/2010. 
Novembro 1996.

[9] Site da Internet:

http://maps.google.com.br/maps?hl=ptBR\&q=oli nda\%20pe\&um=1\&ie=UTF-8\&sa=N\&tab=wl.

Visitadp pela última vez em 01/08/2010.

[10] A.P., Carneiro, B.C.E. Quadros, A.M.V. Oliveira, A.S. Brum, T.S. Sampaio, E.P.V. Alberte, e D.B. Costa,D.B. Características do Entulho e do Agregado Reciclado. In: CASSA, J. C. S.; CARNEIRO, A. P.; BRUM, I. A. S. Reciclagem de Entulho para Produção de Materiais de Construção: Projeto Entulho Bom . Salvador: EDUFBA/ Caixa Econômica Federal, Cap. V, p. 142 - 187, 2001. 